\section{The Lungworm Protostrongylus rufescens in Australia}

OF the lungworms described from domestic sheep only two, namely, Dictyocaulus filaria and Muellerius capillaris, have been identified in Australia ${ }^{1}$, despite careful searching in the eastern States. On one occasion a single larva of Protostrongylus spp. was found in frees of a sheep in Tasmania (Gordon, H. McL., personal communication), but earlier records of the adults are regarded as mistaken ${ }^{1,2}$.

$P$. rufescens has now definitely been identified in lungs of sheep from Millicent, in the south-eastern part of South Australia, and its larvæ in fæces from the flock. Larvæ have also been found in the abomasal contents of a sheep from Kojonup in the south-west of Western Australia. The indications from the large numbers of adults recovered (up to 600 in a single sheep) are that the worm is by no means rare in the south-western part of Australia.

The anatomy conforms in detail with that described by Gerichter ${ }^{3}$ except that the local adults, eggs and firststage larvæ are rather smaller; for example, males are $18-30 \mathrm{~mm}$. and females 28-45 $\mathrm{mm}$. long, against Gerichter's $22-46 \mathrm{~mm}$. and $30-65 \mathrm{~mm}$. respectively. Other authorities ${ }^{4}$ record dimensions comparable with our measurements.

The surface of the affected lungs showed scattered yellowish grey consolidated patches of irregular shape, 3-15 $\mathrm{mm}$. in diameter, identical with those described by Kassai ${ }^{5}$. The worms were found mostly in clumps of up to ten, obstructing bronchioles, with some lying in larger air-vessels. A rapid and highly effective method of extracting the worms is to fill the trachea and bronchi with saline, tip up and down several times, pour out, and repeat the process a number of times.

The material from Kojonup was kindly made available by Dr. I. W. Parnell, of Perth. We wish to thank Mr. A. W. Banks for advice in connexion with this work.

\section{A. Konthals}

Institute of Medical and Veterinary Science, Adelaide.

\section{G. ShenMan}

Millicent, South Australia.

\footnotetext{
${ }^{1}$ Ross, I. C., and Gordon, H. MeL., "The Internal Parasites and Parasitic Diseases of Sheep" (Angus and Robertson, Sydney, 1936).

${ }^{2}$ Seddon, H. R., "Diseases of Domestic Animals in Australia. Part 1. Helminth Infestations" (Government Printer, Sydney, 1950).

serichter, C. B., Parasitol., 41, 166 (1951).

"Lapage, G., "Veterinary Parasitology" (Oliver and Boyd, London, 1956)

${ }^{5}$ Kassai, T., Acta Vet. Lung, 7, 351 (1957).
}

\section{MICROBIOLOGY}

\section{Feedback Control of Tryptophan Biosynthesis}

MickobIoLogists are becoming increasingly intertested in the regulation of biosynthesis. There has been a number of reports of normal metabolites inhibiting the action of enzymes necessary for their own biosynthesis ${ }^{1-8}$, and others of the inhibition of enzyme formation or activity ${ }^{7-9}$. Umbarger ${ }^{1,2}$ has called this type of inhibition 'negative feedback'.

In this laboratory we have been interested in tryptophan biosynthesis, particularly the identification of intermediates in the conversion of anthranilic acid to indoleglycerol phosphate ${ }^{10}$. Moyed and Friedman ${ }^{8}$ have recently demonstrated that tryptophan can inhibit the metabolism of anthranilic acid by a cell-free preparation of Escherichia coli, and considered that the site of inhibition was the condensation of anthranilic acid with 5-phosphoribosyl-1. pyrophosphate. We considered that this interpretation was premature, since the preparation could carry out more than one step and because $\mathrm{N}$-o. carboxyphenyl-D-ribosylamine, the unphosphorylated form of the postulated condensation product, is chemically unstable at biological $p \mathrm{H}$ (ref. 10 and unpublished work by Doy, C. H.). It seemed to us that the site of inhibition might equally well be the Amadori rearrangement step :

cid $\rightarrow$ N-o-carboxyphenyl-D-ribosylamine-5-phosphate

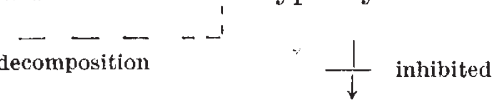

1-(o-carboxyphenylamino)-1-deoxyribulose-5-phosp hate

In any event we suspected that anthranilic acid was only formed by the appropriate tryptophan auxotrophs of Aerobacter aerogenes and Escherichia coli in the absence of growth.

We have now shown (Fig. 1) that Aerobacter aerogenes mutant strain $N C W \cdot T-17 A$, able to respond to indole, but not anthranilic, acid and known to accumulate anthranilic acid in washed-cell experiments with minimal substrates, does not excrete detectable amounts of anthranilic acid until growth on limiting L-tryptophan has ceased. The coincidence of end of growth and the onset of accumulation suggests that tryptophan is able to inhibit a process necessary for the biosynthesis of its own precursor anthranilic acid. Because there was no lag between end of growth and the excretion of anthranilic acid, the inhibition is likely to be on the action of an enzyme rather than on enzyme formation. This conclusion is supported since cells harvested during growth, washed to remove tryptophan and then transferred to minimal substrate, immediately begin to form anthranilic acid (Fig. 2, but note tendency for acceleration). In fact, they form the intermediate at a faster rate than that observed after growth (Fig. 1). This is probably because the fresh substrate represents a condition closer to the optimum.

The conclusion that tryptophan is able to control its own biosynthesis by inhibiting the action of an enzyme necessary for a stage prior to anthranilic acid suggests that the inhibition reported by Moyed and Friedman ${ }^{6}$ is not the earliest site of action and is therefore more of a potential control point than a real one. Since nothing is known of specific tryptophan precursors prior to anthranilic acid, the inhibition now reported makes this part of the pathway particularly important. Because of this lack of knowledge it is also necessary to have reservations about the role of anthranilic acid, since the 'natural' condensa. tion of 5-phosphoribosyl-1-pyrophosphate may be with a compound other than anthranilic acid ${ }^{11}$.

Tryptophan auxotrophs grow well if supplied with L-tryptophan, which suggests that tryptophan does 